\title{
Stereospecific Polymerization of Methacrylates with Ethylmagnesium Alkoxides
}

\author{
Yoshio OKamoto, Kazuhiko Urakawa, and Heimei YukI \\ Department of Chemistry, Faculty of Engineering Science, Osaka University, \\ Toyonaka, Osaka 560, Japan.
}

(Received December 16, 1977)

\begin{abstract}
Ethylmagnesium alkoxides (EtMgOR) resulting from an equimolar reaction of diethylmagnesium $\left(\mathrm{Et}_{2} \mathrm{Mg}\right)$ with a variety of alcohols were employed as catalysts for the stereospecific polymerization of methyl methacrylate (MMA) in toluene at $-78^{\circ} \mathrm{C}$. The catalysts obtained from normal alcohols did not show a clear stereospecific tendency, but the alkoxides of 2-monosubstituted primary alcohols such as 2-methyl-1-propanol (iso- $\mathrm{BuOH}$ ), 2butanol, cyclohexylmethanol, and (-)-cis-myrtanol, worked as isospecific catalysts. Secondary and tertiary alkoxides formed syndiotactic polymers. In the polymerization with $\mathrm{Et}_{2} \mathrm{Mg}$-iso$\mathrm{BuOH}$ system, the activity of the catalyst and the isotacticity of the obtained polymer were highest at [iso- $\mathrm{BuOH}] /\left[\mathrm{Et}_{2} \mathrm{Mg}\right]=1$; the isotacticity decreased with an increase in temperature. The stereospecificity of $\mathrm{Et}_{2} \mathrm{Mg}$-2-methyl-2-propanol $(t-\mathrm{BuOH})$ system did not depend on the $[t-\mathrm{BuOH}] /\left[\mathrm{Et}_{2} \mathrm{Mg}\right]$ ratio; the temperature effect was not pronounced. The stereospecific polymerization of ethyl, tert-butyl, $\alpha$-methylbenzyl, and $\alpha, \alpha$-dimethylbenzyl methacrylates was also investigated with iso-BuOMgEt and $t$-BuOMgEt in toluene at $-78^{\circ} \mathrm{C}$. The structure of the catalysts was investigated by means of the ${ }^{1} \mathrm{H}$ NMR method.

KEY WORDS Stereospecific Polymerization / Diethylmagnesium / Ethylmagnesium Alkoxide / Methyl Methacrylate/ Methacrylate / Tacticity / Anionic Polymerization /
\end{abstract}

Many organomagnesium compounds such as dialkylmagnesium (RMgR), ${ }^{1,2}$ alkylmagnesium amide $\left(\mathrm{RMgNR}^{\prime} \mathrm{R}^{\prime \prime}\right){ }^{3}$ and Grignard reagent $(\mathrm{RMgX})^{1,2}$ have been used as stereospecific catalysts for the polymerization of methacrylic esters. These compounds possess $\mathrm{Mg}$ - carbon, $\mathrm{Mg}-$ nitrogen, and $\mathrm{Mg}$-halide bonds, respectively, in addition to the $\mathrm{Mg}$ - carbon bond. However alkylmagnesium alkoxide ( $\left.\mathrm{RMgOR}^{\prime}\right)$ has scarcely been used for the polymerization of methacrylates. Coates and Ridley have reported that alkylmagnesium alkoxide can be prepared from dialkylmagnesium and alcohol, and forms dimer, trimer, and higher oligomers in benzene depending on both the alkyl group and alkoxy group. ${ }^{4}$ Such an association of alkylmagnesium alkoxides has also been observed even in diethyl ether. ${ }^{5}$

The polymerization of methacrylates catalyzed by alkylmagnesium alkoxides is initiated by an insertion reaction of a monomer molecule into the $\mathrm{Mg}$ - carbon bond. Consequently, the alkoxy group bound to a magnesium cation always stays at a position close to a polymer-chain anion and the structure of the alkoxy group may have an influence on the stereoregulation of the polymerization.

In order to ascertain this point, we undertook the polymerization of methyl (MMA), ethyl (EtMA), tert-butyl ( $t$-BuMA), $\alpha$-methylbenzyl (MBMA), and $\alpha, \alpha$-dimethylbenzyl (DMBMA) methacrylates by using various ethylmagnesium alkoxides (EtMgOR) obtained from equimolar reaction of diethylmagnesium and alcohols in toluene. In particular, the polymerization of MMA with $\mathrm{Et}_{2} \mathrm{Mg}$-2-methyl-1-propanol (iso$\mathrm{BuOH})$ and $\mathrm{Et}_{2} \mathrm{Mg}$-2-methyl-2-propanol ( $t$ $\mathrm{BuOH})$ systems was investigated in detail.

\section{EXPERIMENTAL}

\section{Materials}

Commercial MMA, EtMA, and $t$-BuMA were purified in the usual manner, stored over calcium 
hydride, and distilled on a vacuum line just before use. MBMA and DMBMA were prepared from methacryloyl chloride and the corresponding alcohols and purified by repeated distillation under reduced pressure. Purified toluene was mixed with a small amount of BuLi and distilled under high vacuum just before use. $\mathrm{Et}_{2} \mathrm{Mg}$ was prepared according to the method of Schlenk as follows. $^{6}$ Ethylmagnesium bromide was first prepared in diethyl ether. To this solution dry dioxane was added to precipitate the magnesium bromide-dioxane complex. The $\mathrm{Et}_{2} \mathrm{Mg}$ solution obtained in ether contained about $10-\mathrm{mol} \%$ dioxane against $\mathrm{Et}_{2} \mathrm{Mg}$ and its concentration was determined to be $0.62 \mathrm{~mol} / l$ by acid titration. Except for (-)-prolinol, all other alcohols were purchased from Nakarai, Aldrich, and Merck chemical companies. Liquid alcohols were purified by distillation; their purities were higher than $99 \%$ by gas chromatography. Solid alcohols such as quinine and cinchonine were used without purification. (-)-Prolinol was synthesized by the reduction of L-proline ethyl ester with lithium aluminum hydride. ${ }^{7}$

\section{Preparation of Catalyst}

A catalyst solution was prepared in a dry glass ampoule under a dry nitrogen. Toluene $(10 \mathrm{~m} l)$ and an alcohol $(0.22 \mathrm{mmol})$ were placed in the ampoule and cooled to $0^{\circ} \mathrm{C}$ in all cases unless otherwise stated. To this solution $\mathrm{Et}_{2} \mathrm{Mg}$ in ether was added with a syringe and allowed to react for $10 \mathrm{~min}$. Then, the catalyst solution was cooled to the polymerization temperature. The reaction mixture of equimolar $\mathrm{Et}_{2} \mathrm{Mg}$ and an alcohol usually gave a homogeneous solution in toluene, but when an excess of alcohol was added, the system became heterogeneous.

\section{Polymerization}

To the catalyst solution, MMA (1.0 g) was added. The reaction was run for $150 \mathrm{~min}$ and terminated by adding a few drops of methanol. The polymer was precipitated in methanol containing a small amount of hydrochloric acid and isolated by filtration

\section{Measurement}

${ }^{1} \mathrm{H}$ NMR spectra were taken with a JNM-MH$100(100 \mathrm{MHz})$ spectrometer. Tacticities of PMMA and poly(EtMA) were directly deter- mined from their NMR spectra in $\mathrm{CDCl}_{3}$ at $60^{\circ} \mathrm{C}$; those of other polymethacrylates were obtained from the spectra of PMMA which had been derived from these polymers. ${ }^{8}$ The viscosity of the polymer was measured in toluene at $30.0^{\circ} \mathrm{C}$, the concentration of the polymer being $0.5 \mathrm{~g} / \mathrm{d} l$.

\section{RESULTS}

\section{Polymerization of MMA with Various Ethylmagne- sium Alkoxides}

When the equimolar reaction of $\mathrm{Et}_{2} \mathrm{Mg}$ with $\mathrm{BuOH}$, iso-BuOH, or $t-\mathrm{BuOH}$ was carried out at $0^{\circ} \mathrm{C}$ in toluene-ether mixture, almost the same amount of ethane was formed and about a half of the peaks due to the methylene protons of $\mathrm{Et}_{2} \mathrm{Mg}$ disappeared regardless of the alcohols. This was confirmed by ${ }^{1} \mathrm{H}$ NMR spectroscopy and indicates that the reaction of $\mathrm{Et}_{2} \mathrm{Mg}$ with the alcohols proceeds stoichiometrically.

Table I. Polymerization of MMA with Ethylmagnesium primary alkoxides in toluene at $-78^{\circ} \mathrm{C}$

\begin{tabular}{|c|c|c|c|c|}
\hline \multirow{2}{*}{$\mathrm{ROH}$} & \multirow{2}{*}{$\begin{array}{c}\text { Yield, } \\
\%\end{array}$} & \multicolumn{3}{|c|}{ Tacticity, $\%$} \\
\hline & & $I$ & $H$ & $S$ \\
\hline None & 84 & 6 & 25 & 69 \\
\hline Methanol & 27 & 10 & 29 & 61 \\
\hline Ethanol & 22 & 26 & 21 & 53 \\
\hline 1-Propanol & 26 & 47 & 19 & 34 \\
\hline 1-Butanol & 37 & 24 & 26 & 50 \\
\hline 1-Pentanol & 26 & 57 & 16 & 27 \\
\hline 1-Octanol & 32 & 48 & 20 & 32 \\
\hline 2-Methl-1-propanol(iso-BuOH) & 96 & 91 & 4 & 5 \\
\hline 2-Methl-1-propanol(iso-BuOH) ${ }^{\mathrm{a}}$ & 78 & 87 & 6 & 7 \\
\hline ( \pm )2-Methyl-1-butanol & 94 & 88 & 5 & 7 \\
\hline (-)2-Methyl-1-butanol & 100 & 93 & 3 & 4 \\
\hline Cyclohexylmethanol & 74 & 69 & 11 & 20 \\
\hline (-)-cis-Myrtanol ${ }^{\mathrm{b}}$ & 86 & 71 & 11 & 18 \\
\hline (-)-Prolinol ${ }^{\mathrm{c}}$ & 87 & 7 & 26 & 67 \\
\hline Neopentyl alcohol & 86 & 13 & 24 & 63 \\
\hline 1-Adamantylmethanol ${ }^{\mathrm{d}}$ & 88 & 13 & 22 & 65 \\
\hline Benzyl alcohol & 32 & 13 & 33 & 54 \\
\hline 3-Methyl-1-butanol & 38 & 48 & 20 & 32 \\
\hline
\end{tabular}

${ }^{a}$ Diethyl ether was removed before the polymerization.
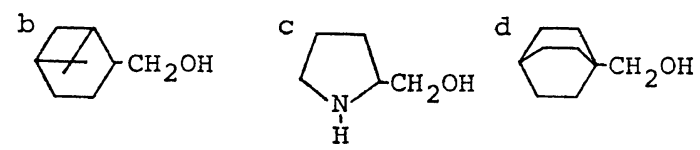
Table I shows the results of the polymerization of MMA with primary alkoxides in toluene at $-78^{\circ} \mathrm{C}$. The polymerization system contained a small amount of diethyl ether and dioxane which were used as the solvents of $\mathrm{Et}_{2} \mathrm{Mg}$. However, the solvents had little effect on the polymerization as will be stated later. Syndiotactic PMMA was obtained in a good yield with $\mathrm{Et}_{2} \mathrm{Mg}$ alone. Normal alkoxides did not show a clear stereospecific tendency and gave so-called stereoblock-or stereoblend-type PMMA in low yields. 2Monosubstituted primary alkoxides except for that of (-)-prolinol yielded isotactic polymer in high yields; these catalysts are called as isospecific catalysts in this paper. However, the alkoxides derived from 2-disubstituted alcohols such as neopentyl alcohol and 1-adamantylmethanol functioned as syndiospecific catalysts. 3-Methyl1-butanol behaved like a normal alcohol.

The results of polymerization with secondary and tertiary alkoxides are shown in Table II. The secondary alkoxides usually formed syndiotactic PMMA in good yields when they were prepared from hydrocarbon alcohols. No difference was observed between the results obtained by $( \pm)$ - and

Table II. Polymerization of MMA with ethylmagnesium secondary and tertiary alkoxides in toluene at $-78^{\circ} \mathrm{C}$

\begin{tabular}{|c|c|c|c|c|}
\hline \multirow{2}{*}{ ROH } & \multirow{2}{*}{$\underset{\%}{\text { Yield, }}$} & \multicolumn{3}{|c|}{ Tacticity, \% } \\
\hline & & $I$ & $H$ & $S$ \\
\hline 2-Butanol & 74 & 11 & 24 & 65 \\
\hline 2-Pentanol & 74 & 14 & 23 & 63 \\
\hline 3-Pentanol & 85 & 7 & 26 & 67 \\
\hline 3-Methyl-2-butanol & 88 & 20 & 24 & 56 \\
\hline Diphenylmethanol & 82 & 10 & 23 & 67 \\
\hline$( \pm)$-Menthol & 94 & 4 & 21 & 75 \\
\hline (-)-Menthol & 93 & 4 & 22 & 74 \\
\hline (-)-Borneol & 100 & 32 & 13 & 55 \\
\hline Quinine & 19 & 31 & 29 & 40 \\
\hline Quinidine & 2 & 58 & 22 & 20 \\
\hline Cinchonine & 43 & 31 & 30 & 39 \\
\hline Cinchonidine & 20 & 24 & 32 & 44 \\
\hline 2-Methyl-2-propanol( $t$-BuOH) & 88 & 12 & 14 & 74 \\
\hline 2-Methyl-2-propanol $(t-\mathrm{BuOH})^{\mathrm{a}}$ & 55 & 9 & 14 & 77 \\
\hline 1-Adamantanol & 82 & 8 & 26 & 66 \\
\hline Triphenylmethanol & 61 & 5 & 24 & 71 \\
\hline Phenol & 19 & 39 & 26 & 35 \\
\hline
\end{tabular}

a Diethyl ether was removed before the polymerization. (-)-menthoxides. However, the initiators derived from the alcohols having heteroatoms like quinine, cinchonine, and their isomers formed so-called stereoblock- or stereoblend-type PMMA, although the polymer yields were low. Tertiary alkoxides functioned analogously to the secondary alkoxides. Phenoxide gave a stereoblend type polymer.

\section{Polymerization of $M M A$ with $E t_{2} M g-i s o-B u O H$ and $\mathrm{Et}_{2} \mathrm{Mg}-\mathrm{t}$-BuOH Systems}

In order to examine the details about the polymerization by these catalysts, we chose $\mathrm{Et}_{2} \mathrm{Mg}$ iso-BuOH system as the isospecific catalyst and $\mathrm{Et}_{2} \mathrm{Mg}-t-\mathrm{BuOH}$ system as the syndiospecific one. Figure 1 represents the results of the polymerization of MMA in toluene at $-78^{\circ} \mathrm{C}$ with the catalysts prepared from various ratios of iso- $\mathrm{BuOH}$ to $\mathrm{Et}_{2} \mathrm{Mg}$. The polymer yield, isotactic triad content $(\mathrm{I} \%)$, and solution viscosity of the polymer were highest at $[$ iso- $\mathrm{BuOH}] /\left[\mathrm{Et}_{2} \mathrm{Mg}\right]=1.0$. This indicates that the reaction product (iso-BuOMgEt) of equimolar iso- $\mathrm{BuOH}$ and $\mathrm{Et}_{2} \mathrm{Mg}$ forms an isotactic active species and the further addition of iso-BuOH leads to a different type of active species which polymerizes MMA in less isotactic manner. With the $\mathrm{Et}_{2} \mathrm{Mg}-t$ - $\mathrm{BuOH}$ system, syndiotactic PMMA was formed regardless of the ratio of $t$ - $\mathrm{BuOH}$ to $\mathrm{Et}_{2} \mathrm{Mg}$.

The change of the tacticity with the polymerization reaction was investigated at [iso- $\mathrm{BuOH}] /$ $\left[\mathrm{Et}_{2} \mathrm{Mg}\right]=1.0$ and 1.5 (Table III). At [iso- $\left.\mathrm{BuOH}\right] /$ $\left[\mathrm{Et}_{2} \mathrm{Mg}\right]=1.0$ the tacticity of the polymer was independent of the polymer yield, while at the ratio 1.5 , the tacticity greatly changed as the polymeri-

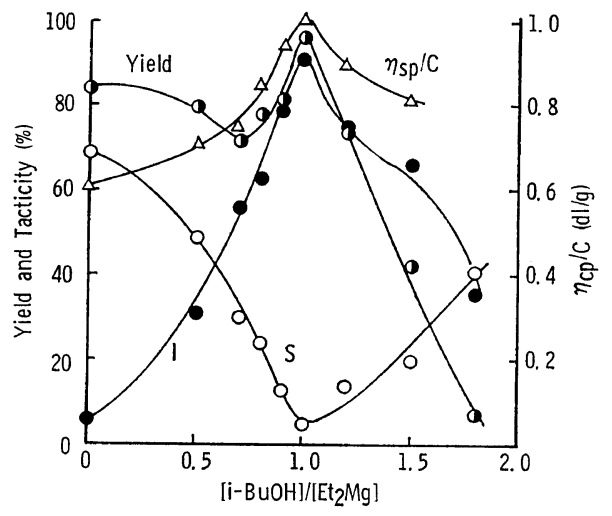

Figure 1. Effect of iso- $\mathrm{BuOH} / \mathrm{Et}_{2} \mathrm{Mg}$ ratio in the polymerization of MMA in toluene at $-78^{\circ} \mathrm{C}$. 
Table III. Polymerization of MMA with the $\mathrm{Et}_{2} \mathrm{Mg}-\mathrm{iso}-\mathrm{BuOH}$ system in toluene at $-78^{\circ} \mathrm{C}$ -Effect of polymerization time-

\begin{tabular}{|c|c|c|c|c|c|c|c|c|c|}
\hline \multicolumn{5}{|c|}{ [iso- $\mathrm{BuOH}] /\left[\mathrm{Et}_{2} \mathrm{Mg}\right]=1$} & \multicolumn{5}{|c|}{ [iso- $\mathrm{BuOH}] /\left[\mathrm{Et}_{2} \mathrm{Mg}\right]=1.5$} \\
\hline \multirow{2}{*}{$\begin{array}{l}\text { Time, } \\
\text { min }\end{array}$} & \multirow{2}{*}{$\begin{array}{c}\text { Yield, } \\
\%\end{array}$} & \multicolumn{3}{|c|}{ Tacticity, \% } & \multirow{2}{*}{$\underset{\mathrm{hr}}{\text { Time, }}$} & \multirow{2}{*}{$\begin{array}{c}\text { Yield, } \\
\%\end{array}$} & \multicolumn{3}{|c|}{ Tacticity, \% } \\
\hline & & $I$ & $H$ & $S$ & & & $I$ & $H$ & $S$ \\
\hline 10 & 12 & 92 & 3 & 5 & 0.5 & 14 & 80 & 8 & 12 \\
\hline 30 & 45 & 90 & 4 & 6 & 1.0 & 22 & 74 & 11 & 15 \\
\hline 90 & 68 & 92 & 3 & 5 & 2.5 & 42 & 66 & 14 & 20 \\
\hline 150 & 96 & 91 & 4 & 5 & 24 & 72 & 43 & 20 & 37 \\
\hline
\end{tabular}

zation proceeded.

The effect of the polymerization temperature was investigated by using iso-BuOMgEt and $t$-BuOMgEt. The results are illustrated in Figures 2

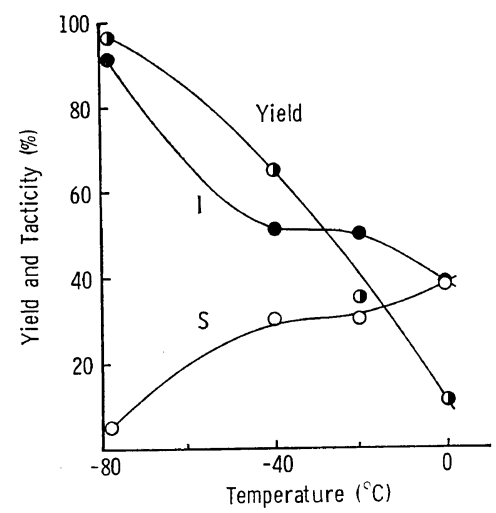

Figure 2. Effect of polymerization temperature in the polymerization of MMA with iso-BuOMgEt in toluene at $-78^{\circ} \mathrm{C}$.

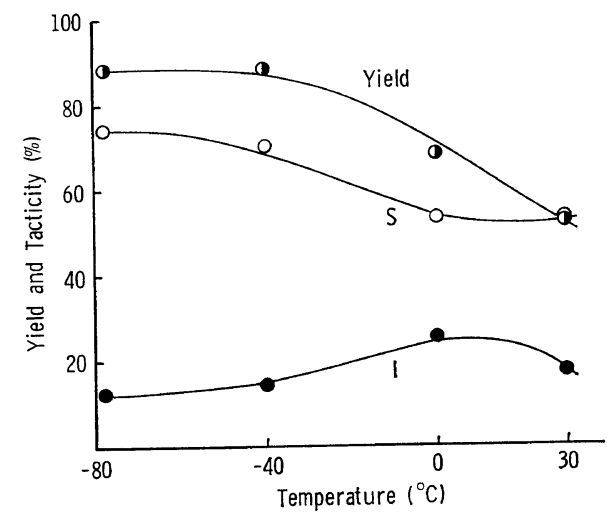

Figure 3. Effect of polymerization temperature in the polymerization of MMA with $t$-BuOMgEt in toluene at $-78^{\circ} \mathrm{C}$. and 3. The yield, solution viscosity, and isotacticity of the polymer obtained with iso-BuOMgEt decreased with an increase in the temperature, whereas less temperature effect was found in the polymerization with $t$-BuOMgEt.

The reaction of $\mathrm{Et}_{2} \mathrm{Mg}$ with the alcohols was run for $10 \mathrm{~min}$ at various temperatures and the polymerization was carried out for $150 \mathrm{~min}$ at $-78^{\circ} \mathrm{C}$ with the resultant alkoxides. The effect of the temperature of the catalyst preparation on the yield and tacticity of polymers are shown in Figure 4 for the iso-BuOMgEt catalyst system. The tacticity of the polymer depended very much on the temperature of the catalyst preparation; above $0^{\circ} \mathrm{C}$, isotactic PMMA and below $-40^{\circ} \mathrm{C}$, syndiotactic PMMA were formed. With $t$-BuOMgEt, however, the effect of the temperature at the catalyst preparation was small.

The diethyl ether which was present in the

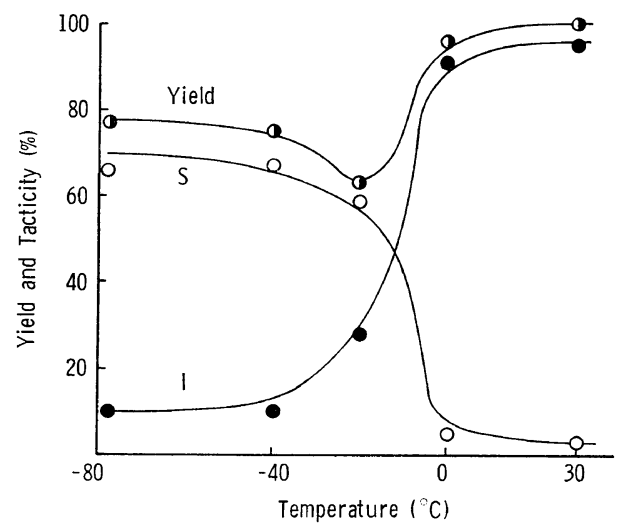

Figure 4. Effect of the temperature of catalyst preparation in the polymerization of MMA with isoBuOMgEt in toluene at $-78^{\circ} \mathrm{C}$. (The reaction of $\mathrm{Et}_{2} \mathrm{Mg}$ with iso-BuOH was carried out for $10 \mathrm{~min}$ at each temperature.) 
catalyst solutions was replaced with toluene by using a vacuum system. The results of the polymerization with ether-free iso-BuOMgEt and $t$-BuOMgEt are listed in Tables I and II. There was no effect of the ether on the polymerization.

The effect of water was also investigated with iso-BuOMgEt. (Table IV). As the amount of water increased, the yield and isotacticity of the polymer decreased.

Table IV. Effect of water on the polymerization of MMA with iso-BuOMgEt in toluene at $-78^{\circ} \mathrm{C}^{\mathrm{a}}$

\begin{tabular}{cccrr}
\hline $\begin{array}{c}\mathrm{H}_{2} \mathrm{O} / \mathrm{Mg}, \\
\mathrm{mol} / \mathrm{mol}\end{array}$ & $\begin{array}{c}\text { Yield, } \\
\%\end{array}$ & \multicolumn{3}{c}{ Tacticity, \% } \\
\cline { 3 - 5 } & & $I$ & $H$ & $S$ \\
\hline 0 & 96 & 91 & 4 & 5 \\
0.1 & 84 & 88 & 5 & 7 \\
0.3 & 51 & 69 & 11 & 20 \\
0.5 & 29 & 59 & 17 & 24 \\
\hline
\end{tabular}

${ }^{a}$ Reaction of iso-BuOMgEt with water was done for $10 \mathrm{~min}$ at $0^{\circ} \mathrm{C}$.

\section{Polymerization of Other Methacrylates}

In Table $\mathrm{V}$ are shown the results of the polymerization of EtMA, $t$-BuMA, MBMA, and DMBMA using iso-BuOMgEt and $t$-BuOMgEt in toluene at $-78^{\circ} \mathrm{C}$. $t$-BuOMgEt yielded polymers rich in syndiotacticity, regardless of the monomers, while iso-BuOMgEt yielded isotactic polymers of EtMA and MBMA and syndiotactic polymers of $t$-BuMA and DMBMA. In the polymerization
EtMA, both the syndiotactic and isotactic of polymers seem to be formed. This indicates that two active species existed in the polymerization. The existence of these two active species has been observed in the polymerization of EtMA with BuLi. ${ }^{9}$

\section{DISCUSSION}

Although the stereospecificity of the ethylmagnesium alkoxides in the polymerization of MMA depended very much on the alkoxy group, the results of the polymerization may be roughly explained in terms of the existence of these two active species; one yields isotactic polymer and the other yields a predominantly syndiotactic polymer. Both species coexist in normal alkoxides; syndiospecific species are predominant in secondary and tertiary alkoxides; and isospecific species are predominant only in 2-monosubstituted primary alkoxides. The structure of these species may be correlated with those of the alkoxides. However, the structure of the alkoxides is not simple because they are usually associated in solutions. ${ }^{4,5}$ The ethylmagnesium alkoxides, especially iso-BuOMgEt, must exist in associated forms judging from the complex catalytic actions. They are likely to be present as mixtures involving the species shown in eq 1 . The higher oligomeric species might coexist but their concentration would be very low under our polymerization conditions.

Table V. Polymerization of methacrylates with iso-BuOMgEt and $t$-BuOMgEt in toluene at $-78^{\circ} \mathrm{C}^{\mathrm{a}}$.

\begin{tabular}{|c|c|c|c|c|c|c|c|c|}
\hline \multirow{3}{*}{ Monomer } & \multicolumn{4}{|c|}{ iso-BuOMgEt } & \multicolumn{4}{|c|}{$t$-BuOMgEt } \\
\hline & \multirow{2}{*}{$\begin{array}{c}\text { Yield, } \\
\%\end{array}$} & \multicolumn{3}{|c|}{ Tacticity, \% } & \multirow{2}{*}{$\begin{array}{c}\text { Yield, } \\
\% \\
\end{array}$} & \multicolumn{3}{|c|}{ Tacticity, \% } \\
\hline & & $I$ & $H$ & $S$ & & $I$ & $H$ & $S$ \\
\hline \multirow[t]{2}{*}{ EtMA } & 5 & 17 & 25 & 58 & 88 & 18 & 13 & 69 \\
\hline & $89^{\mathrm{b}}$ & 72 & 14 & 14 & $11^{\mathrm{b}}$ & 31 & 23 & 46 \\
\hline \multirow[t]{2}{*}{$t$-BuMA } & 76 & 5 & 44 & 51 & 57 & 6 & 33 & 61 \\
\hline & $20^{\mathrm{b}}$ & 15 & 40 & 45 & $38^{\mathrm{b}}$ & 9 & 41 & 50 \\
\hline MBMA & 81 & 64 & 16 & 20 & 80 & 4 & 24 & 72 \\
\hline DMBMA & 53 & 29 & 21 & 50 & 23 & 3 & 19 & 78 \\
\hline
\end{tabular}

a Monomer, $1.0 \mathrm{~g}$; toluene, $10 \mathrm{ml}$; [alkoxide]/[monomer]=1/40; time, $24 \mathrm{hr}$.

b Methanol-soluble part. 


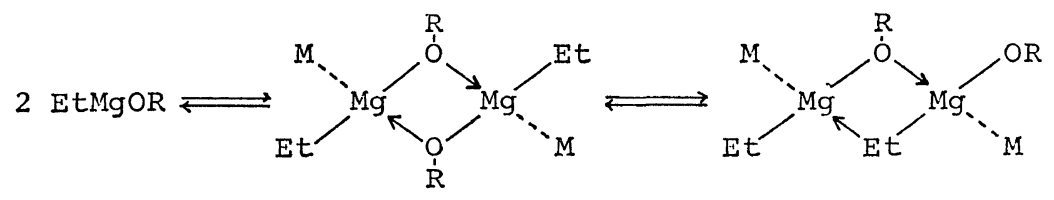

(A)

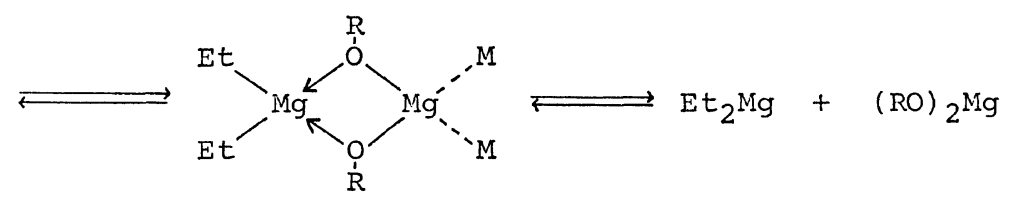

Here $M$ represents MMA or diethyl ether which coordinates with $\mathrm{Mg}$ and is omitted in monomeric forms. Similar equilibria have been proposed for alkylmagnesium alkoxides as well as Grignard reagents. ${ }^{5,10}$ Each species probably initiates the polymerization of MMA to form the polymer with respective tacticity.

The structure of ethylmagnesium alkoxides was investigated by ${ }^{1} \mathrm{H}$ NMR spectrometory in a mixture of toluene and diethyl ether. Figure 5 shows the methylene proton resonances of the ethyl groups of $\mathrm{Et}_{2} \mathrm{Mg}, t$-BuOMgEt, iso-BuOMgEt, and $n$-BuOMgEt at $-78^{\circ} \mathrm{C}$. The latter three spectra were measured after equimolar $\mathrm{Et}_{2} \mathrm{Mg}$ and alcohols had been allowed to react for $10 \mathrm{~min}$ at $0^{\circ} \mathrm{C}$. The methylene resonances appeared on the upfield side of TMS. The reaction of $\mathrm{Et}_{2} \mathrm{Mg}$ with the alcohols was very fast at $0^{\circ} \mathrm{C}$ and even so at $-78^{\circ} \mathrm{C}$, because the formation of stoichiometric amount of ethane was observed immediately after the addition of $\mathrm{Et}_{2} \mathrm{Mg}$ to the alcohols. It has been reported that the reaction of dialkylmagnesium with alcohol proceeds stoichiometrically. ${ }^{11}$ The spectrum of $t$-BuOMgEt was different from those of iso-BuOMgEt and $n$-BuOMgEt. This indicates that the structure of the main species of $t$-BuOMgEt is distinguishable from those of other two. However, these spectral data could not simply be correlated with the results of the polymerization of MMA. Although the NMR spectra of iso-BuOMgEt and $n$-BuOMgEt were rather similar except for small upfield peaks of the former spectrum, the tacticity of the PMMA obtained with these systems greatly differed (Table I). This may indicate that even if the alkoxides have the same structure, their stereospecificity will depend on the alkoxy groups, or that the species assigned to the small upfield peaks of iso- $\mathrm{BuOMgEt}$ is important for isotactic polymerization. The NMR samples in Figure 5 showed little spectral change even at $30^{\circ} \mathrm{C}$, indicating that very stable species were formed in the reaction of $\mathrm{Et}_{2} \mathrm{Mg}$ with each alcohol at $0^{\circ} \mathrm{C}$.

As is shown in Figure 4, the catalytic action of iso-BuOMgEt depended very much on the temperature of the catalyst preparation. We measured the ${ }^{1} \mathrm{H}$ NMR spectrum of the iso-BuO$\mathrm{MgEt}$ which had been prepared by the reaction at $-78^{\circ} \mathrm{C}$ in stead of $0^{\circ} \mathrm{C}$. The spectrum at $-78^{\circ} \mathrm{C}$ is illustrated in Figure $6 \mathrm{a}$ which is very similar to the spectrum of $t$-BuOMgEt in Figure 5. These systems both gave syndiotactic PMMA. The above iso-BuOMgEt was stable at $-78^{\circ} \mathrm{C}$, but at $-20^{\circ} \mathrm{C}$ it gradually changed (Figures $6 \mathrm{~b}-6 \mathrm{e}$ ). Figure 6e resembles Figure $5 \mathrm{c}$ and both catalysts gave isotactic PMMA. Table VI represents the results of the polymerization of MMA using the iso-BuOMgEt obtained under the same reaction conditions as described in Figure 6. The tacticity of the PMMA seems to have a correlation with the spectral change in Figure 6, which therefore may correspond to the change from a syndiosfecific species to an isospecific one.

The structure of the iso-BuOMgEt was presumed from the reaction of $\mathrm{Et}_{2} \mathrm{Mg}$ with (iso- $\mathrm{BuO}$ ) ${ }_{2} \mathrm{Mg}$. $\mathrm{Et}_{2} \mathrm{Mg}$ was added at $-78^{\circ} \mathrm{C}$ into equimolar amount of (iso-BuO) ${ }_{2} \mathrm{Mg}$ which had previously been prepared from $\mathrm{Et}_{2} \mathrm{Mg}$ and two equivalent iso- $\mathrm{BuOH}$. The (iso-BuO) ${ }_{2} \mathrm{Mg}$ was insoluble in a mixed solvent of toluene and ether, but when $\mathrm{Et}_{2} \mathrm{Mg}$ was added 
Polymn. of Methacrylate by Ethylmagnesium Alkoxide

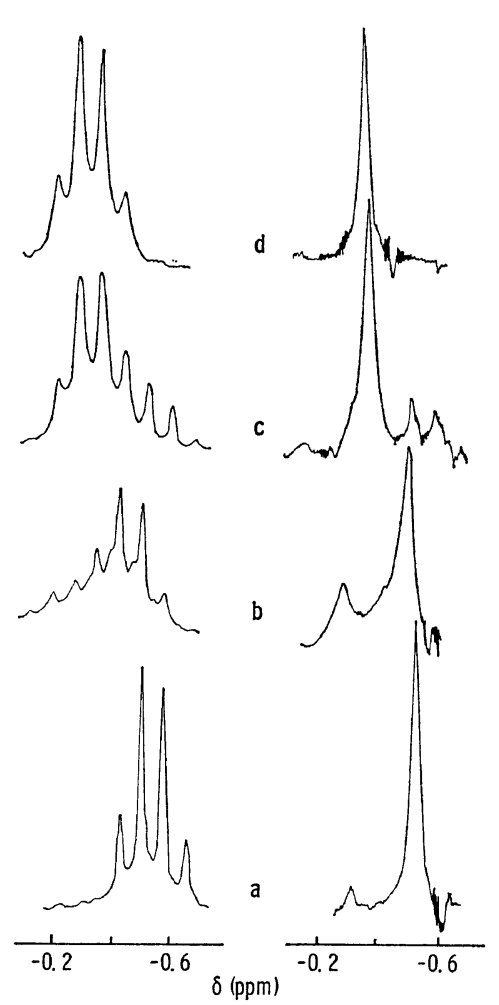

Figure 5. Methylene resonances of the ethyl groups in the ${ }^{1} \mathrm{H}$ NMR spectra at $-78^{\circ} \mathrm{C}$ of $\mathrm{Et}_{2} \mathrm{Mg}$ (a), $t$-BuOMgEt (b), iso-BuOMgEt (c), and $n$-BuOMgEt (d). (The reaction of $\mathrm{Et}_{2} \mathrm{Mg}$ with alcohols was done for $10 \mathrm{~min}$ at $0^{\circ} \mathrm{C}$ in $0.55: 1.0(\mathrm{v} / \mathrm{v})$ tolueneether mixture. The spectra on the right-hand side were obtained by decoupling from methyl protons.)

Table VI. Polymerization of MMA with iso$\mathrm{BuOMgEt}$ in toluene at $-78^{\circ} \mathrm{C}^{\mathrm{a}}$ : Effect of the conditions of catalyst preparation

\begin{tabular}{ccccc}
\hline $\begin{array}{c}\text { Reaction conditions } \\
\text { of } \begin{array}{c}\mathrm{Et}{ }_{2} \mathrm{Mg} \text { with } \\
\text { iso-BuOH }\end{array}\end{array}$ & $\begin{array}{c}\text { Yield, } \\
\%\end{array}$ & \multicolumn{3}{c}{ Tacticity, \% } \\
\cline { 3 - 6 } & \multicolumn{1}{c}{$\boldsymbol{I}$} & $H$ & $S$ \\
$-78^{\circ} \mathrm{C}, 10 \mathrm{~min}$ & 77 & 10 & 24 & 66 \\
$-20^{\circ} \mathrm{C}, \quad 2 \mathrm{~min}$ & 71 & 12 & 24 & 64 \\
$-20^{\circ} \mathrm{C}, \quad 10 \mathrm{~min}$ & 63 & 28 & 23 & 49 \\
$-20^{\circ} \mathrm{C}, 121 \mathrm{~min}$ & 95 & 83 & 6 & 11 \\
\hline
\end{tabular}

a Polymerization time, $150 \mathrm{~min}$.

to this, the mixture dissolved in the solvent. The ${ }^{1} \mathrm{H}$ NMR spectrum of the $\mathrm{Et}_{2} \mathrm{Mg}$-(iso- $\mathrm{BuO}$ ) ${ }_{2} \mathrm{Mg}$ mixture at $-78^{\circ} \mathrm{C}$ is similar to Figure $6 \mathrm{a}$ and the mixture gave syndiotactic PMMA. When the

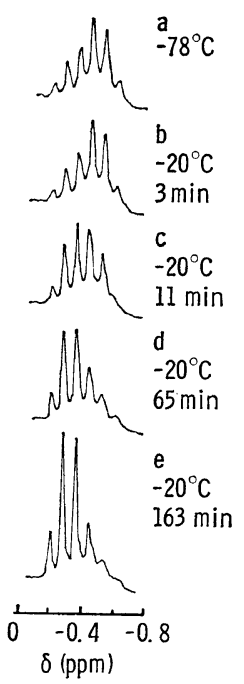

Figure 6. Methylene resonance of the ethyl group in the ${ }^{1} \mathrm{H}$ NMR spectra of iso-BuOMgEt in 0.55: 1.0 $(\mathrm{v} / \mathrm{v})$ toluene-ether mixture. (The reaction of $\mathrm{Et}_{2} \mathrm{Mg}$ with iso-BuOH was done at $-78^{\circ} \mathrm{C}$ and the spectra were measured under the conditions shown in the spectra in the order of $a, b, c, \ldots$ )

mixture was held at $-20^{\circ} \mathrm{C}$, it showed a spectral change very similar to that shown in Figures $6 \mathrm{a}-$ 6e. Consequently, the structure of the $\mathrm{Et}_{2} \mathrm{Mg}-$ (iso-BuO) ${ }_{2} \mathrm{Mg}$ mixture at $-78^{\circ} \mathrm{C}$ appears to be the same as that of iso-BuOMgEt which was prepared at $-78^{\circ} \mathrm{C}$. One of the probable structures for this mixture could be $\mathrm{C}$ in eq 1 , which might isomerize to $\mathrm{A}$ upon being heated at higher temperature. In the polymerization by other syndiospecific ethylmagnesium alkoxides, a small amount of free $\mathrm{Et}_{2} \mathrm{Mg}$ or the species $\mathrm{C}$ in eq 1 may play an important role.

The stereospecificity of the ethylmagnesium alkoxides depended on the ester groups of the monomers (Table V). This is quite reasonable since the stereospecificity should be controlled by the steric interaction between the alkoxy group of a catalyst and a monomer.

If the alkoxy groups of the catalysts have heteroatoms like prolinol, quinine, cinchonine, and cinchonidine, these atoms will interact with the $\mathrm{Mg}$ cation and this interaction will affect the stereospecificity of the catalysts (Tables I and II). Moreover, the further addition of alcohol or water to ethylmagnesium alkoxides will result in the formation of other type of catalysts. ${ }^{10}$ 
From the results of the present study, it is expected that $\mathrm{Et}_{2} \mathrm{Mg}$ - chiral alcohol systems may induce the stereoelective polymerization of racemic methacrylates. Actually, we found that the stereoelective polymerization of MBMA was possible with some of the chiral systems. ${ }^{12}$

\section{REFERENCES}

1. W. E. Goode, F. H. Owens, P. P. Fellmann, and W. H. Snyder, J. Polym. Sci., 46, 317 (1960).

2. A. Nishioka, H. Watanabe, K. Abe, and Y. Sono, J. Polym. Sci., 48, 241 (1960).

3. Y. Joh and Y. Kotake, Macromolecules, 3, 337 (1970).

4. G. E. Coates and D. Ridley, Chem. Commun., 560 (1966).

5. J. A. Nackashi and E. C. Ashby, J. Organometal.
Chem., 35, Cl (1972).

6. W. Schlenk and W. Schlenk, Jr., Ber., 62, 920 (1929).

7. P. Karrer, P. Portmann, and M. Suter, Helv. Chim. Acta, 31, 1620 (1948).

8. H. Yuki, Y. Okamoto, Y. Shimada, K. Ohta, and K. Hatada, J. Polym. Sci., Polym. Chem. Ed., in press.

9. K. Hatada, Y. Umemura, M. Furomoto, S. Kokan, K. Ohta, and H. Yuki, Makromol. Chem., 178, 1215 (1977); K. Hatada, Y. Umemura, and H. Yuki, Preprints of International Symposium on Macromolecules, Dublin, Ireland, 1977, p 63.

10. G. E. Coates, "Organometallic Compounds: I," 3rd ed, Methuen \& Co., Ltd., 1967, p 91.

11. T. Narita, T. Yasumura, and T. Tsuruta, Polym. J., 4, 421 (1973).

12. Y. Okamoto, K. Urakawa, K. Ohta, and $\mathrm{H}$. Yuki, Macromolecules, in press. 